\title{
Pengaruh Pengalaman dan Jarak Tempuh Melaut terhadap Pendapatan Nelayan di Kabupaten Cilacap
}

\author{
Kristian Cahyandi \\ Akademi Maritim Nusantara, Cilacap \\ andykrist94@gmail.com
}

Diterima 31 Januari 2021, direvisi 11 Februari 2021, diterbitkan 08 Maret 2021

\begin{abstract}
Abstrak
Penelitian ini bertujuan untuk menganalisis pengaruh pengalaman dan jarak tempuh melaut secara individu dan bersama-sama terhadap pendapatan nelayan di Kabupaten Cilacap. Kajian tulisan ini menganalisa hal apa yang paling dominan diantara dua variable tersebut terhadap peningkatan pendapatan nelayan di Kabupaten Cilacap. Kajian dengan memakai data primer serta sekunder. Data primer diperoleh melalui sebaran kuesioner kepada nelayan tentang pengalaman dan jarak tempuh melaut di Kabupaten Cilacap. Data tersebut didukung oleh data sekunder lain yang relevan menggunakan Regresi Linier Berganda. Dari hasil kajian nampak bahwa variabel pengalaman dan jarak tempuh melaut berpengaruh secara bersama-sama terhadap pendapatan nelayan di Kabupaten Cilacap. Secara parsial variabel pengalaman berpengaruh signifikan terhadap pendapatan nelayan di Kabupaten Cilacap, sedangkan variabel jarak tempuh melaut tidak berpengaruh signifikan terhadap pendapatan nelayan di Kabupaten Cilacap.
\end{abstract}

Kata Kunci: Pendapatan Nelayan, Pengalaman, Jarak Tempuh Melaut, Regresi Berganda

\begin{abstract}
The study, aims to analyze the effect of fishing experience and distance traveled individually and collectively on fishermen's income in Cilacap Regency. This study also analyzes the most dominant factor between the two variables to increase fishermen's income in Cilacap Regency. The research was conducted using primary and secondary data. Primary data was taken from interviews with fishermen about the experience and distance traveled to sea in Cilacap Regency. This data is supported by other relevant secondary data using Multiple Linear Regression.The results showed that the variables of experience and distance traveled simultaneously affect the income of fishermen in Cilacap Regency. Whereas partially, the experience variable has a significant effect on the income of fishermen in Cilacap Regency, while the variable fishing distance does not have a significant effect on the income of fishermen in Cilacap Regency.
\end{abstract}

Keywords: Fishermen's Income, Experience, Distance Fishing, Multiple Regression 


\section{Pendahuluan}

Jumlah nelayan di Kabupaten Cilacap 15.882 orang dari 24 Kecamatan dengan jumlah nelayan terbanyak yaitu berasal dari Kecamatan Cilacap Selatan sebanyak 7.529 orang. Hasil produk dan Nilai Produk Perikanan Laut di Kabupaten Cilacap setiap tahun mengalami kenaikan cukup tinggi dengan prosentase setiap tahunnya sekitar $70 \%$.

Tabel 1. Produksi dan Nilai Produksi

Perikanan di Kabupaten Cilacap Tahun 2016-2018

\begin{tabular}{lrrr}
\hline \multicolumn{1}{c}{ Jenis } & \multicolumn{3}{c}{ Produksi (ton) } \\
\cline { 2 - 4 } Perairan & 2016 & 2017 & \multicolumn{1}{c}{2018} \\
\hline $\begin{array}{l}\text { Air payau } \\
\text { (tambak) }\end{array}$ & 880.220 & 1.058 .790 & 1.106 .103 \\
$\begin{array}{l}\text { Laut } \\
\text { Air tawar } \\
\text { (kolam) }\end{array}$ & 2.778 .990 & 16.783 .780 & 21.866 .321 \\
$\begin{array}{l}\text { Perairan } \\
\text { umum } \\
\text { (rawa) }\end{array}$ & 88.640 & 146.562 & 79.148 \\
$\begin{array}{l}\text { Genangan } \\
\text { air }\end{array}$ & 171.010 & 269.250 & 100.570 \\
$\begin{array}{l}\text { Perairan } \\
\text { umum } \\
\text { (sungai) }\end{array}$ & 408.370 & 592.540 & 1.027 .094 \\
\hline
\end{tabular}

Sumber : Dinas Perikanan dan Kelautan Kab. Cilacap

Apabila mengamati nilai produksi perikanan tangkap pada Kabupaten Cilacap yang mengalami peningkatan setiap tahunnya, hal ini berarti tingkat pendapatan nelayan seharusnya akan meningkat dan jauh memadai dengan tergambar dari kondisi kehidupan nelayan tersebut. Teori mengatakan bahwa produksi memiliki hubungan dengan pendapatan, seandainya produksi naik tentu pendapatan akan meningkat juga, tetapi kenyataan yang terjadi dari gambaran ekonomi kehidupan masyarakat nelayan di Kabupaten Cilacap pada umumnya belumlah menggambarkan tingkat pendapatan yang menjadi lebih baik.

Kecamatan Cilacap Selatan sebagai sampel terbesar terdiri dari 5 kelurahan. Jumlah nelayan terbanyak terdapat pada Kelurahan Cilacap yaitu sebanyak 4.152 nelayan dari keseluruhan nelayan di Kecamatan Cilacap Selatan sebanyak 7.529. Berdasarkan data tempat tinggal menurut jenis dinding yang dipakai di wilayah Kelurahan Cilacap pada Kecamatan Cilacap Selatan Kabupaten Cilacap ditemukan masih banyak tempat tinggal yang menggunakan dinding bambu yaitu sebesar 2.023 rumah, dari total 2.682 rumah yang menggunakan dinding bambu di Kecamatan Cilacap Selatan [1].

Memperhatikan penyampaian dalam latar belakang serta paparan yang disampaikan oleh karena itu permasalahan yang akan dikaji pada tulisan ini yaitu : (1) Apakah faktor pengalaman dan jarak tempuh melaut secara parsial dan bersama-sama mempengaruhi pendapatan nelayan di Kabupaten Cilacap? ; (2)Manakah diantara kedua variabel yang paling dominan atau paling berpengaruh terhadap peningkatan pendapatan nelayan di Kabupaten Cilacap ?

\section{Materi dan Metode}

\section{Pendapatan}

Pendapatan yang diperoleh Nelayan biasanya bersumberkan dari : pendapatan dari usaha tangkap ikan dan pendapatan dari luar tangkap ikan. Penghasilan pokok dari nelayan berasalkan dari kegiatan tangkap ikan, sedang pendapatan dari luar usaha tangkap ikan, terkadang memiliki nilai yang lebih rendah [2].

\section{Pengalaman}

Pengalaman sebagai sumber pengetahuan, yang dapat berdampak bagi orang lain dengan berbagi pengalaman pada saat mereka mengalami suatu hal, dan dari hal tersebut dapat menyebabkan pengalaman menjadi makin mendalam. Faktor pengalaman secara teori baik dalam buku maupun berbagai literatur tidak didapat yang mengupas akan pengalaman adalah fungsi pada pendapatan atau keuntungan. Akan tetapi, pada kasus kegiatan nelayan yang semakin berpengalaman, para nelayan yang ada peningkatan pengalaman dalam kegiatan tangkap ikan dapat menambah income ataupun keuntungan.

\section{Jarak Tempuh Melaut}

Terdapat tiga bentuk kegiatan tangkap ikan yang biasa dijalani para nelayan. Pertama merupakan kegiatan tangkap ikan lebih dari satu hari. Bentuk tangkap ikan seperti ini adalah bentuk tangkap ikan lepas pantai. Jarak tempuh daerah tangkap dan kapasitas perahu akan mempengaruhi lama melaut. Berikutnya bentuk kegiatan tangkap ikan satu hari. Yaitu semisalkan nelayan melaut sekitar pukul 14.00 akan kembali sekitar pukul 09.00 pada hari berikutnya. Model tangkap ikan tersebut bisa 
dikategorikan sebagai jenis tangkap ikan lepas pantai. Dan yang ketiga adalah pola tangkap ikan pada tengah hari. Kegiatan ini adalah tangkap ikan disekitar pantai. Biasanya nelayan berangkat pukul 03.00 dini hari atau setelah subuh, kemudian kembali pada pagi harinya sekitar jam 09.00.

\section{Kerangka Konsep Penelitian}

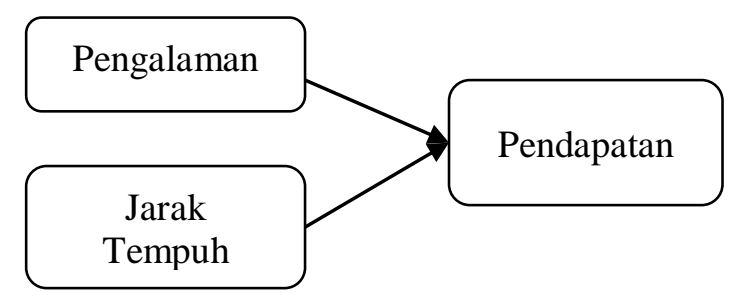

Gambar 1. Kerangka Konsep Penelitian

\section{Hipotesis Penelitian}

H1 : Faktor pengalaman berpengaruh signifikan terhadap pendapatan nelayan di Kabupaten Cilacap

H2 : Faktor JarakTempuh Melaut berpengaruh signifikan terhadap pendapatan nelayan di Kabupaten Cilacap

H3 : Faktor pengalaman merupakan variabel yang paling dominan atau paling berpengaruh diantara dua variable yang diteliti terhadap peningkatan pendapatan nelayan di Kabupaten Cilacap

\section{Metode Penelitian}

Penggunaan metode yaitu metode survei yang menggunakan populasi, sampel, serta responden. Populasi dalam penelitian ini adalah masyarakat nelayan pada wilayah Kecamatan Cilacap Selatan Kabupaten Cilacap pada tahun 2018 yang berjumlah 7.529 orang.

Jumlah sampel ditetapkan melalui Rumus Slovin :

$$
\mathrm{n}=\frac{\mathrm{N}}{1+\mathrm{N}\left(\mathrm{d}^{2}\right)}
$$

Keterangan :

$\mathrm{N}=$ Besar populasi

$\mathrm{n}=$ Besar sampel

$\mathrm{d}$ = Tingkat kepercayaan

$$
\begin{aligned}
& \mathrm{n}=\frac{\mathrm{N}}{1+\mathrm{N}\left(\mathrm{d}^{2}\right)} \\
& \mathrm{N}=7.529
\end{aligned}
$$

$$
\begin{aligned}
\mathrm{d} & =10 \% \\
n & =\frac{7.529}{1+7.529(0,01)} \\
\mathrm{n} & =98,68 \text { dibulatkan } 99
\end{aligned}
$$

Jadi jumlah sampel penelitian ini yaitu sebesar 99 nelayan pada wilayah Kecamatan Cilacap Selatan di Kabupaten Cilacap.

Metode yang dipakai dalam pengumpulan sampel pada penelitian ini yaitu Proportionate Stratified Random Sampling. Berdasarkan survey awal terhadap subyek penelitian ditemukan bahwa subyek penelitian sebagian besar sudah bepengalaman dalam melaut.

Menggunakan Strata : pengalaman. Sampling Frame : 6.248, dengan keterangan 2056 (belum berpengalaman) dan 4192 (sudah berpengalaman)

Jumlah Kategori Strata Dalam Variabel :

Tabel 2. Pengalaman Melaut

\begin{tabular}{cc}
\hline Belum berpengalaman & Sudah berpengalaman \\
\hline 2056 & 4192 \\
$\frac{2056 \times 100}{6.248}=33$ & $\frac{4192 \times 100}{6.248}=66$ \\
\hline
\end{tabular}

Responden pada penelitian ini merupakan nelayan yang tinggal di Kecamatan Cilacap Selatan Kabupaten Cilacap yang ikut tergabung dalam DPC Himpunan Nelayan Seluruh Indonesia (HNSI) Kabupaten Cilacap.

\section{Teknik Analisa Data}

1. Analisis Regresi Linear Berganda

Bentuk persamaan yang digunakan dalam penelitian ini adalah sebagai berikut :

$$
\mathrm{Y}=\mathrm{a}_{0}+\mathrm{b}_{1} \mathrm{X}_{1}+\mathrm{b}_{2} \mathrm{X}_{2}+\varepsilon
$$

Keterangan :

$\mathrm{Y}=$ Pendapatan Nelayan

$\mathrm{X}_{1}=$ Pengalaman

$\mathrm{X}_{2}=$ Jarak Tempuh (Dummy Variabel)

$0 \quad=$ dekat $1=$ jauh

$\mathrm{a}=$ Konstanta

$\mathrm{b}_{1-6}=$ Koefisien regresi

$\varepsilon=$ Error

2. Uji T

Untuk memberikan informasi tentang pengaruh masing-masing variabel bebas secara parsial terhadap variabel tidak bebas 
digunakan uji $\mathrm{t}$, yaitu degan melihat $\mathrm{t}_{\text {hitung }}$ untuk masing-masing variabel bebas < alpha.

$$
t=\frac{b_{j}}{S b_{j}}
$$

Keterangan :

$\mathrm{t}=$ Uji t hitung

bj $\quad=$ Koefisien regresi $\mathrm{ke} \mathrm{j}$

$\mathrm{Sbj}=$ standar error regresi

Perumusan hipotesis :

$\mathrm{H}_{0} \quad$ : bj $=0$ (tidak ada pengaruh masingmasing variabel independen terhadap variabel dependen).

$\mathrm{H}_{1}$ : bj > 0 (ada pengaruh masing-masing variabel independen terhadap variabel dependen).

dengan Derajat Kebebasan (n-k) dan $(\alpha=$ 0,05), maka : $\mathrm{H}_{0}$ diterima jika $\mathrm{t}$ hitung $<\mathrm{t}$ tabel, $\mathrm{H}_{0}$ ditolak jika $\mathrm{t}$ hitung $>\mathrm{t}$ tabel.

\section{Hasil dan Pembahasan}

\section{Pengalaman}

Tabel 3. Pengalaman Nelayan dalam Melaut

\begin{tabular}{ccc}
\hline $\begin{array}{c}\text { Pengalaman } \\
\text { (Tahun) }\end{array}$ & Frekuensi & Persentase \\
\hline 3 & 1 & 1.0 \\
4 & 1 & 1.0 \\
5 & 2 & 2.0 \\
6 & 3 & 3.0 \\
\hline 7 & 7 & 7.1 \\
8 & 21 & 21.2 \\
9 & 9 & 9.1 \\
10 & 37 & 37.4 \\
11 & 8 & 8.1 \\
12 & 5 & 5.1 \\
13 & 2 & 2.0 \\
14 & 3 & 3.0 \\
\hline Total & 99 & 100.0 \\
\hline
\end{tabular}

Pengalaman nelayan dalam melaut terbanyak sebesar 10 tahun dengan prosentase yaitu sebesar $37,4 \%$. Pengalaman dalam melaut akan dianggap memiliki kemampuan yang handal dalam pola tangkap ikan maupun mengetahui titik berkumpulnya ikan, apabila telah melakukan aktifitas tangkap ikan selama lebih dari 5 tahun.

\section{Jarak Tempuh Melaut}

Tabel 4. Jarak Tempuh yang Dipakai dalam Melaut

\begin{tabular}{ccc}
\hline \multicolumn{3}{c}{ darak Tempuh } \\
(Mil) & Frekuensi & Persentase \\
\hline 75 & 2 & 2.0 \\
80 & 7 & 7.1 \\
90 & 22 & 22.2 \\
95 & 4 & 4.0 \\
100 & 40 & 40.4 \\
105 & 2 & 2.0 \\
110 & 10 & 10.1 \\
120 & 8 & 8.1 \\
130 & 1 & 1.0 \\
140 & 2 & 2.0 \\
150 & 1 & 1.0 \\
\hline Total & 99 & 100.0 \\
\hline
\end{tabular}

Berdasarkan data di atas dijelaskan bahwa, jarak tempuh dalam melaut terbanyak sebesar 100 mil dengan prosentase yaitu sebesar $40,4 \%$. 1 mill laut setara dengan $1,8 \mathrm{Km}$ dengan pola penangkapan :

1. Lebih dari 1 hari= Lepas pantai

2. 1 hari $=14.00-09.00 \mathrm{WIB}(19$ jam $) /$ Lepas pantai

3. $1 / 2$ hari $=03.00-09.00$ WIB $(6$ jam $) /$ Dekat pantai

\section{Pendapatan Nelayan}

Tabel 5. Pendapatan Nelayan dari Melaut

\begin{tabular}{ccr}
\hline $\begin{array}{c}\text { Pendapatan } \\
\text { (Dalam Juta }\end{array}$ & Frekuensi & Persentase \\
Rp) & & \\
\hline$\leq 20$ & 19 & 19,2 \\
$20-24$ & 46 & 46,5 \\
$>25$ & 31 & 31,3 \\
\hline Total & 99 & 100.0 \\
\hline
\end{tabular}

Pendapatan nelayan yang dihasilkan dari melaut terbanyak pada interval 20-24 juta dengan prosentase yaitu sebesar 46,5\%. Musim melaut disebut dengan panen raya, dengan hasil tangkapan yang besar adalah pada bulan Juni, Juli, Agustus, September, dan Oktober. 


\section{Analisis Linier Regresi Berganda}

Tabel 6. Uji Regresi Pengaruh Pengalaman, Jarak Tempuh Melaut terhadap Pendapatan

\begin{tabular}{lccc}
\hline Variabel & Koefisien & $\mathrm{T}$ & $\alpha$ \\
\hline Konstan & 1,571 & 9,395 & 0,000 \\
$\begin{array}{l}\text { Pengalaman } \\
\text { (logX1) }\end{array}$ & 0,445 & 2,337 & 0,022 \\
Jarak & 0,021 & 0,674 & 0,502 \\
tempuh & & & \\
(logX2) & & & \\
\hline
\end{tabular}

Dependent Variabel: Pendapatan

Sumber: Data Primer diolah SPSS

Berdasar analisa regresi pada tabel tersebut di atas disampaikan bahwa persamaan regresi yang di peroleh sebagai berikut:

$\log Y=1,571+0,445 \log X_{1}+0,021 \log X_{2}$

Keterangan :

$\log \mathrm{Y}=$ Pendapatan

$\log X_{1}=$ Pengalaman

$\operatorname{LogX}_{2}=$ Jarak Tempuh Melaut

Adapun Interpretasi dari persamaan regresi tersebut yaitu hasil regresi variabel pengalaman ditunjukkan koefisen regresi pengalaman diketahui sebesar 0,445. Memiliki arti, apabila pengalaman meningkat satu persen dan variabel lainnya tetap, maka pendapatan meningkat 0,445 persen.

Koefisen regresi jarak tempuh diketahui sebesar 0,021. Artinya, apabila jarak tempuh meningkat satu persen dan faktor lainnya tetap, maka pendapatan meningkat 0,021 persen.

Makna hasil analisis regresi terhadap nilai konstanta sebesar 1,571 menunjukkan nilai ratarata pendapatan meningkat sebesar 1,571 persen apabila semua variabel yang diteliti tidak mengalami perubahan.

$\mathrm{R}^{2}$ adalah perbandingan antara variasi semua variabel bebas secara bersama-sama terhadap pendapatan. Hasil penelitian diperoleh $\mathrm{R}^{2}$ sebesar 0,957. Hal ini menunjukkan pengaruh variabel bebas terhadap pendapatan sebesar $95,7 \%$, sisanya $4,3 \%$ ditentukan oleh variabel lain di luar model.

Berdasarkan Tabel 6 maka dapat diperoleh beberapa analisis:

\section{Pengaruh Pengalaman terhadap Pendapatan Nelayan}

Terlihat variabel pengalaman dengan menggunakan level of significant $\alpha=5 \%$ berpengaruh signifikan terhadap pendapatan nelayan karena memiliki tingkat signifikansi sebesar 0,022 yang lebih kecil dari taraf signifikansi 0,05. Hasil ini menunjukkan bahwa variabel pengalaman mempunyai pengaruh signifikan terhadap pendapatan nelayan. Semakin berpengalamannya nelayan makin tinggi berpeluang mendapat hasil tangkap yang lebih banyak, dikarenakan kegiatan nelayan terutama pada nelayan skala kecil tidak mempergunakan pedoman atau teknologi dalam menentukan lokasi tangkap ikan, namun hanya dengan mengandalkan pengalaman kerja dilaut.

\section{Pengaruh jarak tempuh melaut terhadap pendapatan nelayan}

Dapat terlihat bahwa variabel jarak tempuh dengan memakai level of significant $\alpha=5 \%$ tidak berpengaruh signifikan terhadap pendapatan nelayan karena memiliki tingkat signifikansi sebesar 0,502 yang lebih besar dari taraf signifikansi 0,05 . Hasil ini menunjukkan bahwa variabel jarak tempuh tidak mempunyai pengaruh signifikan terhadap pendapatan nelayan.

\section{Pengaruh Paling Dominan terhadap Pendapatan Nelayan}

Berdasarkan hasil penghitungan persamaan matematis regresi diperoleh koefisien regresi variabel pengalaman sebesar 0,445 , variabel jarak tempuh sebesar 0,021. Dari hasil regresi diketahui bahwa variabel yang mempunyai pengaruh signifikan yaitu variabel pengalaman.

\section{Kesimpulan}

1. Variabel pengalaman dan jarak tempuh melaut, secara bersamaan memiliki pengaruh terhadap pendapatan nelayan di Kabupaten Cilacap. Secara parsial, variabel pengalaman memiliki pengaruh terhadap pendapatan nelayan di Kabupaten Cilacap, sedangkan variabel jarak tempuh melaut tidak memiliki pengaruh terhadap pendapatan nelayan di Kabupaten Cilacap.

2. Faktor pengalaman merupakan variabel paling dominant atau paling memiliki pengaruh terhadap peningkatan pendapatan nelayan di Kabupaten Cilacap.

\section{Ucapan terima kasih}

Penulis mengucapkan terimakasih kepada AMN atas dukungan finansialnya pada 
penelitian ini dan nelayan di kabupaten Cilacap atas dukungannya dalam keikutsertaan kegiatan ilmiah ini.

\section{Daftar Pustaka}

[1] Badan Pusat Statitistik (BPS), "Kabupaten Cilacap dalam Angka”, BPS, Cilacap, 2019.

[2] Sajogyo, "Garis Kemiskinan dan Kebutuhan Minimum Pangan", Aditya Media, 1996.

[3] Rokhmin Dahuri, "Membangun Kelautan dan Perikanan”, Bening, Jakarta, 2008.

[4] Dr. Soekidjo Notoatmojo, 2010, Metodologi Penelitian, Rineka Cipta, Bandung.

[5] Himpunan Nelayan Seluruh Indonesia (HNSI), "Laporan Tahunan HNSI DPC Cilacap Tahun 2018”, HNSI, Cilacap, 2018.

[6] N. Gregory Mankiw, "Mikro Ekonomi, Erlangga", Jakarta, 2006. 